\title{
Triangulating Multi-Method Assessments of Parental Support for Early Math Skills
}

\author{
Heather J. Bachman ${ }^{1 *}$, Leanne Elliott ${ }^{2}$, Shirley Duong ${ }^{3}$, Laura Betancur ${ }^{3}$, \\ Monica G. Navarro ${ }^{1}$, Elizabeth Votruba-Drzal ${ }^{3}$ and Melissa Libertus ${ }^{3}$
}

${ }^{1}$ Department of Health and Human Development and the Learning Research and Development Center, University of Pittsburgh, Pittsburgh, PA, United States, ${ }^{2}$ Learning Research and Development Center, University of Pittsburgh, Pittsburgh, PA, United States, ${ }^{3}$ Department of Psychology and the Learning Research and Development Center, University of Pittsburgh, Pittsburgh, PA, United States

Past research has examined parental support for math during early childhood using parent-report surveys and observational measures of math talk. However, since most studies only present findings from one of these methods, the construct (parental support for early math) and the method are inextricably linked, and we know little about whether these methods provide similar or unique information about children's exposure to math concepts. This study directly addresses the mono-operation bias operating in past research by collecting and comparing multiple measures of support for number and spatial skills, including math talk during semi-structured observations of parent-child interactions, parent reports on a home math activities questionnaire, and time diaries. Findings from 128 parents of 4-year-old children reveal substantial within-measure variability across all three data sources in the frequency of number and spatial activities and the type and content of parent talk about number and spatial concepts. Convergence in parental math support measures was evident among parent reports from the questionnaire and time diaries, such that scale composites about monthly number activities were related to number activities on the previous work day, and monthly spatial activities were correlated with spatial activities the prior nonwork days. However, few parent report measures from the survey or time diary were significantly correlated with observed quantity or type of math talk in the semi-structured observations. Future research implications of these findings are discussed.

Keywords: math, parenting, structured observation, time diary, home numeracy

\section{INTRODUCTION}

Children's early math learning is gaining widespread interest and investment. Individual differences in children's math skills during early childhood are associated with a wide array of academic, health, and economic characteristics in later adolescence and adulthood. Growth in math skills between preschool and 1st grade predict academic achievement broadly in middle childhood and adolescence (Watts et al., 2016). Moreover, early math skills are related to a range of human capital and labor market outcomes in adulthood, such as educational attainment, earnings, socioeconomic status (SES), and mental and physical health (Murmane et al., 2000; Rose and Betts, 2004; Parsons and Bynner, 2005; Kaufman et al., 2008; Ritchie and Bates, 2013; Weinberger, 2014; Cortes et al., 2015; Hanushek and Woessman, 2015). 
Despite the importance of these early skills for later academic success and adult well-being, growing concerns have been raised about the low quantity and quality of math exposure that most young children experience at home (National Research Council, 2009). However, this concern has been difficult to ascertain from large, longitudinal studies in the United States because parents of preschool-aged children or kindergartners have historically been asked very few questions about their support for early math learning (e.g., Early Childhood Longitudinal Study-Birth cohort; NICHD Study of Early Child Care and Youth Development; ECLS-Kindergarten cohorts). In addition, the few items commonly asked tend to focus on number sense. For example, in the ECLS-K:2011 cohort, parents of kindergarteners were asked how often they practice "reading, writing, or working with numbers" in a week, which combined math and literacy promotion, and only included numeric skills to address math support. However, for young children, emergent math skills include important domains such as geometry, spatial thinking, and measurement, as well as number sense (Klibanoff et al., 2006; Sarama and Clements, 2009), and these early skills promote later math proficiency in procedural and conceptual skills (Ginsburg et al., 2008; National Research Council, 2009). In the present study, we focus on parental support of both number sense and spatial math skills as these are the most widely studied math constructs for young children.

As described in more detail below, the limitations of existing measures of parental support for early math skills as well as the inconsistencies in their interrelations call for a more detailed exploration of various approaches to measure potentially infrequent or episodic math exposure (Cannon and Ginsburg, 2008; Elliott and Bachman, 2018; Elliott et al., 2020). In the present study, we examine an additional methodological approach used across multiple disciplines (economics, sociology, psychology, anthropology) as a tool to capture infrequent math activities during children's daily lives: time diaries. Asking parents to recount their previous day, minute by minute, may unearth brief, episodic math-related activities that could be missed or underestimated in a survey about math activities during the prior week or month, or infrequent interactions that are not captured in short observations of math talk. As mentioned above, a further concern is that the predominant focus on early math support has involved children's developing number sense, with less work focusing on children's developing spatial skills despite their importance for math development.

Thus, the present study addresses two major aims. First, it examines individual differences in parental support for number sense and spatial skills across multi-method assessments, including questionnaires, observed math talk, and time diaries. Second, it identifies areas of triangulation or convergence in the assessment of parental support for number sense and spatial skills across these multi-method data sources. To this end, in the current study we explore the variability in parents' activities and conversations to support early math learning. We also examine the associations among parent questionnaire responses, observed frequencies of math talk, and time diaries to examine the extent to which multiple data sources converge in the assessment of parent support for early math development.

\section{Measurement of Parental Home Math Support Parent Reports in Questionnaires}

Home math activity scales are a commonly used to measure parents' support of young children's math skills (see Elliott and Bachman, 2018 for review). Investigators commonly ask parents about the weekly or monthly frequency of a wide array of activities in the home that may support children's math development, such as counting and sorting objects, playing with number flashcards, or playing card or board games. However, many studies that asked parents about the frequency of a more diverse set of math activities report very low frequencies of math exposure. For example, one study finds that parents of 3- to 5-year-old children in the United States reported engaging their children in math activities such as grouping and ordering objects less than 1-2 times per week, and widely known math activities such as counting occurred only 3-5 times per week on average (Blevins-Knabe and Musun-Miller, 1996). Furthermore, other work finds that more advanced math activities such as comparing numerical magnitudes and arithmetic occur less frequently than counting and grouping (Zippert and Ramani, 2017) and numeracy activities occur more frequently than spatial activities (Zippert and RittleJohnson, 2020; Zippert et al., 2020). This problem is not constrained to the United States: Chilean parents reportedly engage their 4-year-old children in operational activities such as learning simple sums or measuring quantities only weekly on average (Susperreguy et al., 2020). Similar results have been obtained from parents of Greek and Canadian 5-year-olds (LeFevre et al., 2010).

In addition, global composite measures from these inventories of math activities inconsistently predict children's math skills (Kleemans et al., 2012; Missall et al., 2014; Niklas and Schneider, 2014; DeFlorio and Beliakoff, 2015; Hart et al., 2016; Purpura et al., 2020). To address the heterogeneity within these survey items, some researchers have tried to distinguish formal versus informal activities, with explicitly didactic math activities (e.g., number flash cards, writing numerals) compared to more playbased or everyday activities that could provide opportunities to learn math concepts (e.g., board games or cooking) or numeracy and spatial activities. This dichotomy has also produced very mixed findings rather than clarifying key parenting practices that promote early math learning. Some studies report positive associations for formal (LeFevre et al., 2010; Manolitsis et al., 2013; Huntsinger et al., 2016) and informal activities (LeFevre et al., 2009) and math skills. Others report negative associations between informal activities and math skills (Huntsinger et al., 2016), or null associations for formal (Blevins-Knabe and MusunMiller, 1996; LeFevre et al., 2009) and informal activities (LeFevre et al., 2010) and math skills. Furthermore, only numeracy activities seem to be related to both children's numeracy and spatial skills in one study (Purpura et al., 2020), while another study shows that parental report of spatial activities may be 
negatively associated with parent report of children's math skills, albeit a weak association (Hart et al., 2016).

Given the unclear theoretical definitions for formal and informal math activities, the mixed empirical findings regarding their respective relations to children's math skills, and relative dearth of studies on a distinction between numeracy and spatial math activities, the present study explores the latter distinction. Specifically, we examine the consistency with which parents' support of number sense and spatial skills are evident across multiple methods and data sources. In doing so, we aim to address the predominant focus on number sense with a cadre of measurement tools that involve the frequency and duration of spatial activities as well.

\section{Observations of Parental Math Talk}

In an effort to understand whether the low frequency of reported math activities are capturing young children's experiences or may be an artifact of the most widely used tool to measure such exposure - parental questionnaire reports - researchers have explored the frequency of math talk during parent-child observations as an alternate measure of parent support of early math skills. Survey measures of how frequently parents engage in math activities cannot assess whether parents and children are actually discussing math concepts during those interactions, the range of mathematical concepts discussed during these conversations, the qualitative features of the math talk, or math talk that occurs outside of the context of math activities. Rather than focusing on specific activities that are thought to elicit conversation about math, measuring math talk allows researchers to observe math-related interactions that occur during a variety of different activities, regardless of whether they are typically categorized as math-related or not. For example, parents frequently engage in conversations about mathematical concepts during mealtimes even though the activity itself is not be considered math-related (Susperreguy and Davis-Kean, 2016).

The amount and diversity of parents' math talk has repeatedly displayed positive associations with children's math skills (Casey et al., 2018). These relations are most commonly demonstrated with parents' use of number words. For example, parental number talk during naturalistic home observations when children were between 14 and 30 months of age was predictive of children's understanding of cardinality at 46 months after accounting for SES and overall parent talk (Levine et al., 2010). Similarly, studies using structured tasks to elicit math talk in more controlled environments generally find that greater parental number or spatial talk is associated with higher math and spatial skills (Vandermaas-Peeler et al., 2012; Ramani et al., 2015; Elliott et al., 2017; Leyva et al., 2017; but see Zippert et al., 2020, for null results). For example, Vandermaas-Peeler et al. (2012) contrasted the frequency of parental number talk and child responses to parent number talk during dyadic interactions between a numeracy awareness group, in which parents explicitly received suggestions to incorporate numeracy into the activity (e.g., counting and identifying numbers), and a control group. Parents in the numeracy awareness group talked more about number concepts (they incorporated twice as much number talk) compared to controls. Children who were exposed to more questions about number produced more correct responses to parental talk, particularly for more complex math concepts such as arithmetic. Moreover, many of these studies reveal differences in the amount of number talk depending on the nature of the tasks or instructions given to parents (e.g., Vandermaas-Peeler et al., 2012; Ramani et al., 2015; Zippert et al., 2020), suggesting the importance of considering the observational context when measuring math talk. However, parental math talk also seems to occur at very low frequency in young children's everyday lives (Tudge and Doucet, 2004; Gunderson and Levine, 2011). For example, Levine et al. (2010) found that parents of 14- to 30 -month-olds used only an average of 91 number words (e.g., the number words "one" through "ten") over a duration of $7.5 \mathrm{~h}$, ranging from 4 to more than 250 number words.

More recently, several studies have examined parents' use of spatial terms and discussions of spatial content with their young children, either independently or combined with number talk (e.g., Zippert et al., 2019, 2020). Although some studies suggest that children's exposure to spatial talk from their parents is positively associated with children's own spatial language as well as their spatial skills (Pruden et al., 2011; Casasola et al., 2020), others fail to find such a relation (Zippert et al., 2020). In one experimental manipulation, Polinsky et al. (2017) found that providing parents with prompts to discuss spatial content while playing with their children at a museum led to increases in parents' spatial talk as well as children's spatial talk and, in turn, children's performance on a spatial task. Furthermore, much like parental number talk, the frequency of parents' spatial talk varies systematically across different types of activities (Ferrara et al., 2011; Zosh et al., 2015; Ho et al., 2018; Lee et al., 2019; Verdine et al., 2019; Zippert et al., 2020). We extend this further by considering the relations between frequencies of number and spatial talk between parents and children as they engage in different activities.

Despite the consistency in previous results, few studies have explored the qualitative features of parents' math talk. Most studies examine the quantity of number and spatial words, but differential patterns of prediction are increasingly detected across types of math content. For instance, Elliott et al. (2017) found that parents' talk about numbers greater than 10 , not parents' overall number talk, was associated with 5- and 6-year-old children's math skills. Similarly, Casey et al. (2018) found that parental talk about labeling sets of objects with children at age 3 was predictive of children's later math achievement in preschool and first grade after controlling for other forms of numerical support, such as input about identifying numerals and counting. Thus, math talk is not a unitary construct, as parents may emphasize different concepts or children may benefit more from specific forms of number/math talk under varying circumstances (e.g., the nature of the activity, child age, etc.).

In addition to differences in the content being discussed during parent-child interactions, verbal input and scaffolding can occur in the form of questions, directives, or statements (see Mermelshtine, 2017 for a review). Variation in parental language input by utterance format has been explored in the language domain, but evidence is mixed regarding whether questions, statements, or both predict children's language skills 
(Ard and Beverly, 2004; Strouse et al., 2013; Tompkins et al., 2017). On the one hand, through statements, parents can provide rich descriptions or explanations of the events occurring within an activity, expand on their child's utterances, or rephrase their child's speech with more detail or complex vocabulary. On the other hand, questioning can encourage children to verbalize their current knowledge, generate inferences, problem solve, or engage in a higher quantity and diversity of verbal responses (Tompkins et al., 2017).

There is a dearth of studies examining the format through which math talk is conveyed. A numerical statement like, "There are three raccoons and two owls, so there are five animals altogether" focuses a child's attention on numerical information, specifically the link between addends and their sum. For instance, a math question asking, "If each corn is two dollars, how much do I owe you?" requires a child to use higher-order reasoning skills and arithmetic, which likely involves taking multiple steps to respond if multiplication has not yet been learned. In past work, the frequency of parents' questioning during home activities has been associated with children's vocabulary and verbal reasoning (e.g., Rowe et al., 2017) and math skills (Reynolds et al., 2019). However, Casey et al. (2018) categorized parental math input as elicitations (e.g., questions) or statements and reported no differences in how each type of math utterances predicted children's concurrent and later math achievement. Given the varying forms and functions of utterances, we examine whether qualitative aspects of parents' talk about numeric and spatial math content are related to the quantity of their math talk or the frequency of their math activity time at home.

\section{Time Diaries}

Another method of assessing the amount of math exposure that children experience is to collect time diaries, a minute-by-minute report of parent and child activities over the course of $24 \mathrm{~h}$ for parents' work days and non-work days. Time diaries provide a reliable measure of the quantity of academic or educational activities, but studies using this methodology have tended to focus on literacy and reading activities (Juster and Stafford, 1985; Robinson and Godbey, 1999; Phipps and Vernon, 2009). For example, a national longitudinal study from Australia found that the time that children spent in educational activities with parents, which included time reading a story, being talked to, or helping with chores, predicted higher scores in receptive vocabulary and reasoning (Fiorini and Keane, 2014). Similarly, in a study of children under age 13 in the United States, learning activities such as reading for pleasure and structured playing time were associated with higher scores in standardized reading and math tests (Hofferth and Sandberg, 2001). However, previous research has focused on characterizing time spent on broadly defined educational activities or in reading activities (Hofferth and Sandberg, 2001; Price, 2010; Fiorini and Keane, 2014). There is no research to date that has used time diaries to characterize the frequency of math-related activities that occur at home for preschool-aged children. Our collection of time use diaries provides a novel depiction of how and when parents of preschoolers integrate math learning opportunities into their daily schedules.
Time diaries have some advantages when compared with observational and questionnaire methodologies for collecting detailed information about daily routines and activities (Gunthert and Wenze, 2011). Ecological validity is likely stronger in time diaries than structured observations, capturing naturalistic daily family rhythms and activities. In comparison to survey methods, time diaries can minimize recall bias because participants report on a full day of occurrences instead of being prompted to report on one prioritized activity. Also, time diaries are usually collected on the same-day or next-day, and thus participants memory errors decrease in comparison to retrospective surveys that inquire about the time spent in activities over the prior week or month. In addition, time diaries also serve as a bridge between survey and observational methods because of the smaller measurement scale when compared to survey data and the increase in within-subject variability when contrasted with structured observations. In other words, because time diaries are collected multiple times per participant, they provide important information on day-to-day fluctuations in time use. However, like surveys, time diaries indicate the frequency with which activities occur but provide no data on the math content of conversations occurring during those activities.

\section{A Multi-Method Approach to Studying Parental Support of Early Math Skills}

It is unusual for studies to collect and examine multi-method assessments of parental support for math, such as parent reports of home math activities with observed parent math talk. As a consequence, mono-operation bias is prevalent across much of this work, such that the construct under study (i.e., parental support of early math skills) is interwoven with the measurement error in its operationalization (Cook and Campbell, 1979). To date only a handful of studies have combined parent reports of math activities with direct observations of parent math talk. In a sample of low-SES 3- to 5-year-old children and their families, parent reports of math activities but not direct observations of math talk predicted children's foundational number knowledge (e.g., counting), while parents' advanced math talk but not their report of math activities predicted children's advanced number knowledge (e.g., arithmetic) (Ramani et al., 2015). However, Ramani et al. (2015) did not test the association between parent report of math activities and their math talk directly. Missall et al. (2017) observed math-related engagement of parent-child dyads in a semi-structured play session and asked parents to report on the frequency of math activities in the home. They found that these two measures of math input were not correlated. Similarly, Mutaf Yildiz et al. (2018) observed parents' number talk during two structured observations and found that number talk was unrelated to parents' reports of math activities at home. Additionally, survey measures were positively related to children's math performance, whereas parental number talk was negatively associated with math skills. Finally, Thippana et al. (2020) examined number talk during naturalistic free play at home and measured both parental number talk and time spent in math-related activities, finding that both were positively correlated with parental reports of math activities. However, 
number talk at home and parent reports of math activities were both positively associated with children's math skills. Thus, extant work shows inconsistent patterns in the relations between observed parent math input and parental reports warranting further exploration. Importantly, when inconsistencies are found across studies in the predictive validity of any one home learning measure to predict math outcomes, there is little supporting data available to corroborate patterns or provide greater breadth of information about the nature and frequency of parent-child interactions and conversations about math. Furthermore, no work has examined these cross-method associations in parental support of spatial math skills.

One methodological approach to address these measurement limitations is triangulation across methods and data sources (Mathison, 1988; Heath, 2015). To be most effective, the different measures assessing a construct (in this case, parental support of early math) would involve different sources of measurement error, such as differences in methods, response biases, and sources (Heath, 2015). In the present study, triangulation involves collecting in-depth measures of preschoolaged children's math exposure across multiple modalities (i.e., questionnaires, structured observations, and time diary interviews). This approach can provide a richer picture of individual variability in how parents support math than provided by a single measure. In addition, the low frequency of parent-child interactions about math detected in naturalistic assessments (e.g., Tudge and Doucet, 2004) results in a high degree of skewness that makes analyses of the math exposure at home susceptible to floor effects. Combining data across multiple sources could provide more normal distributions of practices and enhance measurement sensitivity. It should be noted that attempts at triangulating multiple assessments of the same construct may not necessarily point to areas of convergence (Mathison, 1988). However, identifying areas of divergence across assessments could also provide valuable breadth of information about math exposure. For example, parents' questionnaire responses provide a global indication of the frequency and type of typical math routines and activities with children. A structured observation facilitates parents and children's shared attention on math games and activities when distractions are minimized and siblings are cared for by research staff. In addition, time diaries capture reports of activities closer to their actual occurrence and can add more detailed information regarding the frequency, duration of and the context in which math activities take place.

The present study draws on multi-method data from multiple sources and modalities to provide an in-depth description of the parental math support for preschool-aged children $(N=128)$ within a socioeconomically diverse sample. First, we will examine within-method variability and interrelations for measures within each data source: parent questionnaires, math talk during semistructured observations, and time diaries. Second, to triangulate across methods and data sources, convergence of methods will be examined with correlations. Since these are novel and exploratory research aims, directional hypotheses are not applicable, although we speculate that shared mono-reporter bias across parent reports (Cook and Campbell, 1979) may result in higher intercorrelations among the parent questionnaires and time diaries than with observed math talk codes.

\section{MATERIALS AND METHODS}

\section{Participants}

This study draws data from the Parents Promoting Early Learning study (PPEL), a community-based longitudinal study of 128 parents of 4-year-old children. Families were recruited from a large, mid-Atlantic metropolitan area through the distribution of fliers in the community and in-person contact between the study team and potential participants at preschools and childcare centers. Data were primarily collected in participants' homes although several families requested to meet in our lab. A socioeconomically diverse sample of families participated: parents reported annual incomes between $\$ 1,000$ and $\$ 425,000$, with a median of $\$ 95,000$ ( $\mathrm{SD}=\$ 73,776)$, and the sample included parents who did not finish high school (2\%) parents with a high school diploma only (6\%), parents with an Associate's degree $(6 \%)$, parents who completed vocational or technical training after high school (2\%), parents who completed some college (9\%), parents with a Bachelor's degree (33\%), and parents with or pursuing a graduate degree (43\%). Overall, children were on average 4 years, 4 months old at the first assessment, and $51 \%$ were female. Most participating parents were biological or adoptive mothers (94\%) and were on average 36 years old (range $=24-56$ years). Parents also reported their employment (40\% full-time, 27\% part-time), marital status (73\% married), and race/ethnicity (80\% White, 11\% Black or African American, 9\% Asian, Latino, multiracial, or other).

\section{Measures and Procedures}

Data were collected from parents during home visits, phone calls, and electronic questionnaires. During the first home visit, parent-child interactions with structured tasks were videorecorded. Measures of math talk were drawn from these structured observation tasks. Directly after the first home visit, parents were sent an electronic link via Qualtrics to complete background questionnaires and questions about the frequency of home math activities. Following the first home visit, parents also received two phone calls on separate days to complete the time diaries for the previous days (one work day and one non-work day). Parents and children also completed batteries of cognitive assessments not discussed here. All research activities were approved by the local Institutional Review Board (Protocol PRO19070136), and all parents gave written informed consent to participate in the study prior to completing any research activities.

\section{Measures of Home Math Exposure Parent reports on home math activities}

Parents completed questionnaires designed to assess the frequency of numeracy and spatial activities at home over the last month (LeFevre et al., 2009). Parents were given a list of 40 activities in the home and asked to report how frequently parents and children engaged in each on a scale from 1 ("did 
not occur") to 5 ("almost daily"; LeFevre et al., 2009). Of these items, 22 were identified as math activities based on theory (e.g., "counting objects," "playing board games with die or a spinner," or "playing with puzzles"). Parents' responses on 18 of these items that we categorized as number-related were averaged to form a composite representing numeracy exposure in the home $(\alpha=0.88)$, with higher scores indicating more frequent engagement with number-related learning activities. Similarly, responses on four items categorized as spatial-related were averaged to form a spatial exposure composite $(\alpha=0.68)$. Item-level descriptive statistics are shown in Table $\mathbf{1 .}$

\section{Observations of math talk during semi-structured parent-child interactions}

Parents and children were observed while they engaged in two semi-structured observation tasks designed to elicit number or spatial talk. To measure number talk, researchers provided dyads with developmentally appropriate toys for pretend grocery shopping, including a shopping basket, cash register, pretend money, and a play set of food items. Parents were instructed to play with these toys with their child as they normally would for $8 \mathrm{~min}$. Previous research has shown that a pretend grocery store can elicit high levels of math-related talk (Elliott et al., 2017). To elicit spatial talk, parents and children completed a magnet board puzzle task during which they are given magnets of various colors and shapes and asked to create an animal. "Guided play" tasks like this elicit high frequencies of spatial talk in parents and children (Ferrara et al., 2011). Dyads played for up to $8 \mathrm{~min}$ in the puzzle activity. Each task was videotaped, transcribed verbatim at the utterance-level, and checked by trained research assistants. An utterance was defined as any language input from an individual speaker that is bounded by silence of at least two seconds, a speaker transition, or a grammatical closure, e.g., a terminal punctuation mark such as a period (Pan et al., 2004).

Transcriptions from direct observation tasks were coded for the quantity and diversity of number and spatial talk. Specifically, the total number of numeric utterances during the grocery task was calculated, and then each numeric utterance was coded for the utterance content: identifying number symbols, counting, labeling sets, ordinal relations, patterning, comparing magnitudes, arithmetic, and other abstract number talk (e.g., talk about time, money, ages; see Table 2). The total number of spatial utterances during the magnet board task was also calculated, and each spatial utterance was also coded for the utterance content: shapes, locations, directions and orientations, features and properties, deictics, spatial dimensions, and continuous amount (see Table 2). Additionally, utterance type was coded for each instance of number and spatial talk as either a statement or question (see Table 3). It should be noted that number and spatial talk measures reported below are based on raw frequency counts. Accounting for overall levels of parents' talkativeness by dividing the frequencies of number and spatial talk by the total number of parent utterances respectively yielded the same pattern of results. These additional analyses are available from the authors upon request.

Coders for both number and spatial talk included graduate students, postdoctoral researchers, undergraduate research assistants, and full-time research staff. Following standard practices (Hallgren, 2012; Chorney et al., 2015), inter-rater reliability on the number and spatial codes for each task was assessed for over $20 \%$ of the sample by calculating the kappas for each code between pairs of coders in identifying and categorizing each math utterance. The initial coder's classification was used in the case of disagreements. For number talk, coders examined a total of 2,964 utterances that were flagged as potentially number-related (based on their inclusion of number words or elicitations). Ordinal relations, patterning, and comparing magnitudes occurred infrequently and were not reliably coded, and so these categories were excluded from analyses. Across utterance content codes, kappas ranged from 0.69 (for other) to 0.91 (for counting), reflecting a moderate to strong degree of reliability in labeling utterances across number talk categories (McHugh, 2012). Additionally, kappas were quite high for identifying number statements and questions (both kappas $=0.95)$. For all number talk kappa statistics, reliability was calculated at the utterance level from the full set of utterances. For example, when calculating reliability for utterances involving counting, cases of disagreement could include times where one coder did not identify the utterance as math talk at all and the second coded it as counting as well as times where one coder identified the utterance as a different type of math talk than counting when the second coded it as counting. This method seemed to be the most conservative approach, as coders would have to both correctly identify an utterance as math talk and code it in the correct category of content or utterance type in order to count as agreement.

For spatial talk, coders examined a total of 1,759 utterances. Frequent spatial content codes had almost perfect agreement between coders (e.g., kappas $=0.91$ for both shapes and spatial dimensions) whereas less frequent codes (e.g., spatial features) were coded moderately reliably (kappas $=0.63$ ). Utterance type was also coded reliably for spatial talk, with kappas of 0.91 and 1.00 for identifying questions and statements, respectively. Similar to number talk, agreement was considered as both identifying the utterance as spatial talk and coding the same content or type.

\section{Time diaries}

Parents completed two time diary interviews over the phone, during which they reported all activities carried out by parents and children over a work day and a non-work day. If the parent worked every day or was not employed, the time diaries were completed to reflect activities on a weekday and a weekend day. In total, 108 participants completed time diaries for both a work day and non-work day, and 14 participants only completed one time diary on either a work day or non-work day. The time diary data were collected using a modified format of the American Time Use Survey (U. S. Bureau of Labor Statistics, 2016). The phone interview occurred 1 day after the target day to facilitate accurate recollection of activities. Parents reported all of their activities and their child's activities starting at $4 \mathrm{AM}$ on the target day and ending at 4 AM 1 day later. Parents reported the primary activities, secondary activities (i.e., activities that take place simultaneously), and where and with whom those activities 
TABLE 1 | Item-level descriptive statistics for number and spatial activities at home.

\begin{tabular}{|c|c|c|c|c|}
\hline Number activities & $M$ & $S D$ & Min & Max \\
\hline Using number arithmetic flashcards & 1.55 & 1.11 & 1 & 5 \\
\hline Identifying names of written numbers & 3.47 & 1.38 & 1 & 5 \\
\hline Playing with number fridge magnets & 1.65 & 1.14 & 1 & 5 \\
\hline Counting objects & 4.56 & 0.71 & 2 & 5 \\
\hline Counted down $(10,9,8,7, \ldots)$ & 2.92 & 1.42 & 1 & 5 \\
\hline Learning simple addition (e.g., $2+2=4$ ) & 2.51 & 1.37 & 1 & 5 \\
\hline Printing numbers & 2.49 & 1.38 & 1 & 5 \\
\hline Talking about money when shopping (e.g., "Which costs more?") & 2.33 & 1.28 & 1 & 5 \\
\hline Measuring ingredients when cooking and/or baking & 2.57 & 1.06 & 1 & 5 \\
\hline Being timed & 2.78 & 1.50 & 1 & 5 \\
\hline Playing with calculators & 1.59 & 1.01 & 1 & 5 \\
\hline "Connect-the-dot" activities & 2.14 & 1.09 & 1 & 5 \\
\hline Using calendars and dates & 2.72 & 1.43 & 1 & 5 \\
\hline Having your child wear a watch & 1.53 & 1.10 & 1 & 5 \\
\hline Using number activity books (e.g., "color-by-number") & 2.34 & 1.36 & 1 & 5 \\
\hline Reading number storybooks & 2.76 & 1.26 & 1 & 5 \\
\hline Playing board games with a die or spinner & 2.58 & 1.23 & 1 & 5 \\
\hline Playing card games & 2.28 & 1.18 & 1 & 5 \\
\hline \multicolumn{5}{|l|}{ Spatial activities } \\
\hline Sort things by size, color, or shape & 3.67 & 1.27 & 1 & 5 \\
\hline Making collections & 2.61 & 1.40 & 1 & 5 \\
\hline Putting pegs in a board or shapes into holes, playing with puzzles & 3.03 & 1.24 & 1 & 5 \\
\hline Building Legos or construction set (Duplo, Megablocks, etc.) & 3.73 & 1.15 & 1 & 5 \\
\hline
\end{tabular}

took place. Following Kotila et al. (2013), audio recordings of the parents' primary activity reports were coded into broader categories of math- and non-math related activities by trained research assistants. Importantly, time diary methods have been used widely with families of diverse backgrounds in the American Time Use Survey (Nesteruk and Garrison, 2005; Lee et al., 2016).

Minutes of time use from child time diary (TD) schedule. We modified the American Time Use Survey (ATUS) codes for the present study to better capture the content of preschool-aged children's academic and recreational activities, rather than using a more global ATUS code like "academic time." In addition, we also clustered some of adults' activities in the ATUS (e.g., paying bills, packing bags, etc.) into gross codes (e.g., domestic work). Some additional editing of the time diary interview and codes occurred after piloting the time diary method with 50 families of preschool-aged children. Refer to Table 4 for a list of the final codes used. Overall time reported that the child was engaged in math activities, either as the primary or secondary activity, was summed for both work days and nonwork days. Again, the primary and secondary activities typically occurred simultaneously and "primary" indicates the first activity mentioned by parents, rather than "primary" indicating a predominant focus during those activity minutes.

Time and frequency of academic stimulation activities. In addition, at the end of the time diary interview we asked parents to report whether a list of math and literacy activities had occurred the previous day. The goal of this additional step was to detect any activities that may not have been reported in the daily 24-h report, such as having a conversation about counting while driving to daycare or playing with a puzzle during a lengthy period of play that was characterized by the parent as "general play at home." The list of math activities was identical to the items in the parent report (LeFevre et al., 2009). Due to interviewer error, approximately 14-17 parents were not asked about each item on the list (typically only missing one item or duration), so the amount of missing data is larger for the academic stimulation activities than for the 24$\mathrm{h}$ time diaries. Many parents struggled to estimate the minutes of time that children engaged in math activities, particularly for those activities that occurred naturally throughout the day (e.g., counting), and so minutes in math activities were estimated at the aggregate level (e.g., "How much time was spent in any math games, including puzzles, board games with a card or spinner, or building with Legos or construction sets"). As such, estimates of time in math activities could not be disaggregated into number and spatial activities, although we report them separately for work days and non-work days. From this list of academic stimulation activities, we also counted the number of activities that did or did not occur the previous work day or non-work day. The number of spatial and numeracy activities occurring on each day were summed; these two measures were also summed to calculate an overall math activity composite.

Coding reliability. Time diary coders included graduate students, undergraduate research assistants, and full-time research staff. To ensure inter-coder reliability, $20 \%$ of time diaries were 
TABLE 2 | Number and spatial utterance content codes.

\begin{tabular}{|c|c|c|}
\hline Code & Definition & Examples \\
\hline Identifying number symbols & $\begin{array}{l}\text { Labeling of or identifying an Arabic numeral } \\
\text { Describing how to spell a number word } \\
\text { Providing general commentary about number symbols }\end{array}$ & $\begin{array}{l}\text { "Look at this number, five." } \\
\text { "Can you point to the number two?" } \\
\text { "What numbers are on that cash register?" }\end{array}$ \\
\hline Counting & $\begin{array}{l}\text { Asking the other person to count } \\
\text { Conversations about counting }\end{array}$ & $\begin{array}{l}\text { "There were one, two, three..." } \\
\text { "Let's count." } \\
\text { "What types of things do we count?" }\end{array}$ \\
\hline Labeling the set size & Referring to or labeling the number of elements in a set & $\begin{array}{l}\text { "Let's see how many foxes there are." } \\
\text { "How many coins are there?" } \\
\text { "There are three foxes." }\end{array}$ \\
\hline Ordinal relations & Describing the order of numbers & $\begin{array}{l}\text { "Tell me what comes after the number two." } \\
\text { "What comes before nine?" }\end{array}$ \\
\hline Patterns & $\begin{array}{l}\text { Identifying common repeating elements of objects, people, actions, or } \\
\text { events }\end{array}$ & $\begin{array}{l}\text { "There are two raccoons, three birds, then } \\
\text { four..." }\end{array}$ \\
\hline Comparing magnitudes & $\begin{array}{l}\text { Describing or identifying a numerical match or mismatch between two } \\
\text { or more discrete quantities }\end{array}$ & $\begin{array}{l}\text { "You have four more pizza slices than I do." } \\
\text { "It looks like you have double that amount." }\end{array}$ \\
\hline Arithmetic & $\begin{array}{l}\text { Statements or questions requiring the use of operations, such as } \\
\text { adding or subtracting } \\
\text { Includes using a full or partial equation including the total } \\
\text { Includes specifying the total if there was a calculation previously implied } \\
\text { Providing commentary about calculations }\end{array}$ & $\begin{array}{l}\text { "One plus one is two." } \\
\text { "How much do I owe you if each corn is \$2?" } \\
\text { "We added two numbers together." }\end{array}$ \\
\hline Other abstract math talk & $\begin{array}{l}\text { Requiring the other person to map something numerical to an abstract } \\
\text { idea } \\
\text { Referencing dates or times }\end{array}$ & $\begin{array}{l}\text { "It's five o' clock at the park in this book." } \\
\text { "Can you pass me a ten dollar bill?" }\end{array}$ \\
\hline Spatial dimensions & Describing the size of objects, people, and spaces & $\begin{array}{l}\text { "We don't need the big purple one." } \\
\text { "Can you get the shorter rectangle?" }\end{array}$ \\
\hline Shapes & $\begin{array}{l}\text { Describing the standard or universally recognized form of enclosed 2- } \\
\text { or 3-D objects and spaces }\end{array}$ & $\begin{array}{l}\text { "Now find the green square." } \\
\text { "How many sides does a triangle have?" }\end{array}$ \\
\hline Locations, directions, and orientations & $\begin{array}{l}\text { Describing the relative position, orientation, or transformation of } \\
\text { objects, people, or points in space }\end{array}$ & $\begin{array}{l}\text { "Move toward the bottom." } \\
\text { "That piece should be sideways." }\end{array}$ \\
\hline Continuous amount & $\begin{array}{l}\text { Describing the amount of continuous quantities within the spatial } \\
\text { domain, including the extent of an object, space, or liquid }\end{array}$ & $\begin{array}{l}\text { "That is one half of the giraffe's body." } \\
\text { "That piece is the exact same as that one." }\end{array}$ \\
\hline Deictics & Utterances that rely on place deictics or pro-forms & $\begin{array}{l}\text { "If you move that piece there and this other } \\
\text { piece here, they will be in the correct place." }\end{array}$ \\
\hline Spatial features and properties & $\begin{array}{l}\text { Describing the features and properties of 2- or 3-D objects, spaces, } \\
\text { people, or the properties of their features }\end{array}$ & $\begin{array}{l}\text { "We are looking for the one with a flat side and } \\
\text { a curved edge." }\end{array}$ \\
\hline
\end{tabular}

double coded (Hallgren, 2012; Chorney et al., 2015). Given that the time-diary reports of minutes spent on math activities during the previous day were measured continuously, the interclass correlation (ICC) across coders was calculated to check reliability, which was 0.89 . Few significant inconsistencies were detected in the codes about time spent in math activities. When

TABLE 3 | Math utterance type codes.

\begin{tabular}{lll}
\hline Code & Description & Example \\
\hline Statement & Any utterance made that & "There's two circles." \\
& does not explicitly elicit an & "You just did addition!" \\
answer from the other & "Let's count these \\
& person; typically declarative & oranges." \\
& Also includes prompts or & "Give me that twenty dollar \\
& imperatives & bill." \\
Question & Any utterance made that & "How many raccoons are \\
& asks a question & there?" \\
& & "How many owls would \\
& there be if two of them
\end{tabular}

inconsistencies among coders occurred, a third expert coder assessed the audio and made a final coding determination.

For the academic stimulation activities measures, ICCs between the coders on each of the assessed numeracy and spatial items were also calculated for both whether an activity occurred as well as the continuous number of minutes in math activities. Specifically, the composite of four spatial activities was highly reliable, with ICCs for whether or not each activity was coded during the day ranging from 0.97 (sorting things) and 1.00 (playing with puzzles and playing with building sets). The numeracy activities composite included 20 items. Several activities were very infrequent, and thus harder to calculate reliability, such as connect the dot activities or wearing a watch. For the remaining 18 items, ICCs were moderate to high, ranging from 0.76 (identifying numbers) to 1.00 (playing with flashcards, playing with fridge magnets, printing numbers, other written number activities, counting, measuring while cooking, using number story books, painting by number, and playing card games). Additionally, reliability for estimates of durations of activities from the academic stimulation measure were high, with ICCs ranging from 0.81 (time in all activities involving math 
TABLE 4 | Time diary items.

\begin{tabular}{|c|c|c|}
\hline \multicolumn{2}{|c|}{ Time use items } & \multirow{2}{*}{$\begin{array}{l}\text { Academic stimulation } \\
\text { Using written numbers }\end{array}$} \\
\hline General activities & Child activities & \\
\hline 1. Sleeping & 27. Preschool & Using number or arithmetic flashcards \\
\hline 2. Grooming/hygiene & 27A. Center & Identifying names of written numbers \\
\hline 2A. Parent & 27B. Home & Playing with number fridge magnets \\
\hline 2B. Child & 27C. Religious & Printing numbers \\
\hline 2C. Give/rec. med/first-aid & 28. Household chores & Playing with calculators \\
\hline 3. Watching TV & 29. Play and recreation at home & Categorizing or counting \\
\hline 3A. Traditional TV & 29A. Arts & Counting objects \\
\hline 3B. Electronic device & 29B. Music & Sorting things by size, color, or shape \\
\hline 4. Eating and drinking & 29C. Blocks/building/puzzles & Making collections \\
\hline 5. Religious activities & 29D. Dramatic & Counting down \\
\hline 6. Errands & 29E. Gross motor & Learning simple sums \\
\hline 7. Interacting family and friends & 29F. Fine motor & Using math while shopping or cooking \\
\hline 7A. From household & 29G. Playing video games & Talking about money when shopping \\
\hline 7B. Not-household & $29 \mathrm{H}$. Electronic media & Measuring ingredients while cooking \\
\hline 7C. Scolding/negative emotion & 29I. Nature/science activities & Talking about dates or times \\
\hline 8. Shopping & 29J. Other & Using calendars and dates \\
\hline 8A. Grocery & 30. Play and recreation out home & Using a watch, clock, or timer \\
\hline 8B. Food/meals & 30A. Arts & Having conversations about time \\
\hline 8C. Other & 30B. Music & Timing child doing something \\
\hline 9. Transportation & 30C. Blocks/building/puzzles & Books or activities that involve math \\
\hline 9A. Car & 30D. Dramatic & Using number activity books \\
\hline 9B. Bus & 30E. Gross motor & Reading number storybooks \\
\hline 9C. Walking & 30F. Fine motor & Paint by number activities \\
\hline 9D. Bike & 30G. Playing video games & Connect the dot activities \\
\hline 10. Resting/leisure & $30 \mathrm{H}$. Electronic media & Playing games that could involve math \\
\hline 11. Child bed time & 30I. Nature/science activities & Board games \\
\hline 12. Other & 30J. Other & Card games \\
\hline Parent activities & 31. Math & Puzzles \\
\hline 13. Working at job & 31A. Hard copy & Legos or construction sets \\
\hline 14. Attend class or studying & 31B. Electronic device & Using video or computer games \\
\hline 15. Preparing meals or snacks & 31C. Talking/interaction & Using educational software \\
\hline 16. Cleaning & 32. Reading & Playing other videogames \\
\hline 17. Laundry & 32A. Hard copy & Reading a book or magazine. \\
\hline 18. Other domestic work & 32B. Electronic device & [If so] While you were reading did you... \\
\hline 19. Reading & 32C. Talking/interaction & Ask questions about what is being read \\
\hline 19A. Electronic device & 33. Other out of home activities & Ask child reading or filling in words \\
\hline 19B. Hard copy & 33A. Museum & Talk about what happened in the story \\
\hline 20. Use phone/electronic media & 33B. Zoo & Point things in pics/ask child to point \\
\hline 21. Exercising & 33C. Library & Child pretend to read \\
\hline 22. Playing with child & 33D. Park & Doing any work with letters or words \\
\hline 23. Academic work with child & 33E. Other & Playing rhyming games \\
\hline 24. Nursing/caring child & 34. Other academic work & Learning the names of the letters \\
\hline 25. Supervising child & 34A. Foreign languages & Playing with alphabet toys at home \\
\hline \multirow[t]{3}{*}{ 26. Interacting with partner } & 34B. Writing & Pointing out letters or words \\
\hline & 34C. Rhyming or word games & Pretending to read independently \\
\hline & 34D. Other & \\
\hline
\end{tabular}

activity or story books) to 1.00 (time discussing time and dates, time spent playing games involving math).

\section{RESULTS}

We first examined individual differences within each data source (i.e., parent questionnaires, math talk, and time diaries) and then examined patterns of correlations across data sources to identify areas of convergence or triangulation.

\section{Parent Reports on Home Math Activities Scale}

Parents' reports of the frequency of math activities at home over the past month are shown in Table 5, including separate 
frequencies for numeracy and spatial activities. In general, these math activities occurred on average between a few times a month (2) and once a week (3). Means were similar but slightly higher for spatial activities than for number activities, but these two survey measures were highly correlated, $r(118)=0.59, p<0.001$.

\section{Observations of Math Talk During Semi-Structured Parent-Child Interactions \\ Number Talk}

During the grocery task, parents used between 7 and 408 utterances $(M=154.82, S D=49.45)$. Of these utterances, approximately $14 \%$ were coded as number-related (see Table 5).
As noted in the methods section, the most frequent math content involved labeling set sizes, counting, and identifying number symbols, with over 14 instances of labeling sets and 2 instances of parents counting and identifying number symbols. As is shown in Table 6, intercorrelations among the utterance content codes were generally positive and significant, with the highest correlations among counting, labeling set sizes, and arithmetic ( $r$ s $=0.33-0.38$ ). However, the frequency of parents' identification of number symbols was unrelated to all number codes aside from the "other abstract number talk" category. The intercorrelation of utterance type number codes was higher than any intercorrelations among the utterance number content codes, such that the frequencies of number statements were correlated 0.53 with the frequency of number questions (see Table 7 ).

TABLE 5 | Descriptive statistics for parental math support measures.

\begin{tabular}{|c|c|c|c|c|c|}
\hline & $n$ & $M$ & $S D$ & Min & Max \\
\hline Home math activities scale & 120 & 2.63 & 0.61 & 1.36 & 4.32 \\
\hline Numeracy activities & 120 & 2.49 & 0.61 & 1.39 & 4.22 \\
\hline Spatial activities & 120 & 3.25 & 0.87 & 1 & 5 \\
\hline \multicolumn{6}{|l|}{ Number talk } \\
\hline Total number utterances & 119 & 21.05 & 14.18 & 0 & 67 \\
\hline \multicolumn{6}{|l|}{ Utterance content } \\
\hline Identifying number symbols & 119 & 2.38 & 4.58 & 0 & 29 \\
\hline Counting & 119 & 2.15 & 3.35 & 0 & 20 \\
\hline Labeling sets & 119 & 14.55 & 9.74 & 0 & 47 \\
\hline Arithmetic & 119 & 0.80 & 1.90 & 0 & 11 \\
\hline Other abstract math talk & 119 & 1.37 & 2.29 & 0 & 13 \\
\hline \multicolumn{6}{|l|}{ Utterance type } \\
\hline Number statements & 119 & 14.24 & 11.04 & 0 & 46 \\
\hline Number questions & 119 & 8.39 & 6.52 & 0 & 37 \\
\hline \multicolumn{6}{|l|}{ Spatial talk } \\
\hline Total spatial utterances & 119 & 60.42 & 34.26 & 0 & 163 \\
\hline \multicolumn{6}{|l|}{ Utterance content } \\
\hline Shapes & 119 & 11.78 & 9.70 & 0 & 43 \\
\hline Locations, directions and orientations & 119 & 18.51 & 11.44 & 0 & 69 \\
\hline Features and properties & 119 & 1.94 & 3.00 & 0 & 24 \\
\hline Deictics & 119 & 15.44 & 9.52 & 0 & 61 \\
\hline Spatial dimensions & 119 & 4.61 & 4.30 & 0 & 21 \\
\hline Continuous amount & 119 & 11.87 & 7.71 & 0 & 37 \\
\hline \multicolumn{6}{|l|}{ Utterance type } \\
\hline Spatial statements & 119 & 38.71 & 21.96 & 0 & 139 \\
\hline Spatial questions & 119 & 25.47 & 17.74 & 0 & 94 \\
\hline \multicolumn{6}{|l|}{ Time diary (TD) codes } \\
\hline Minutes of math time, work day: Child TD schedule & 114 & 4.42 & 15.51 & 0 & 90 \\
\hline Minutes of math time, non-work day: Child TD schedule & 115 & 8.64 & 31.93 & 0 & 215 \\
\hline Minutes child was awake/not at preschool, work day & 109 & 569.59 & 208.94 & 214 & 960 \\
\hline Minutes child was awake/not at preschool, non-work day & 112 & 736.07 & 111.53 & 205 & 992 \\
\hline Minutes of parent work, work day & 114 & 291.65 & 246.33 & 0 & 847 \\
\hline Minutes of parent work, non-work day & 116 & 21.29 & 65.80 & 0 & 405 \\
\hline Minutes of math time, work day: Acad. stim. activities & 101 & 45.99 & 42.15 & 0 & 212 \\
\hline Minutes of math time, non-work day: Acad. stim. activities & 104 & 71.22 & 68.42 & 0 & 375 \\
\hline Number activities on a work day & 100 & 3.22 & 1.73 & 0 & 8 \\
\hline Number activities on a non-work day & 98 & 3.45 & 2.14 & 0 & 10 \\
\hline Spatial activities on a work day & 111 & 0.60 & 0.85 & 0 & 4 \\
\hline Spatial activities on a non-work day & 109 & 0.93 & 0.87 & 0 & 3 \\
\hline Math activities on a work day & 100 & 3.78 & 2.05 & 0 & 10 \\
\hline Math activities on a non-work day & 98 & 4.37 & 2.60 & 0 & 12 \\
\hline
\end{tabular}




\section{Spatial Talk}

Parents used between 29 and 296 utterances during the magnet board task with their children $(M=140.00, S D=54.14)$. As is shown in Table 3, 43\% of these utterances were coded as containing spatial talk. Locations, directions and orientations talk was most frequent, as parents used these terms in over 18 utterances on average, followed by deictics with an average of 15 utterances. As is shown in Table 6, almost all spatial talk codes were weakly to highly intercorrelated ( $r s=0.23-0.64)$, with the exception of deictics with features and properties and discussion of continuous amount. Spatial utterances were also coded as either statements or questions. As shown in Table 7, these frequencies were also modestly correlated $(r=0.29)$.

\section{Intercorrelations Among Number and Spatial Talk}

In addition to these within-domain associations, we also examined the extent to which parents who used more number talk also used more spatial talk during the observational tasks. Overall counts of number talk and spatial talk were not significantly correlated, $r(112)=0.11, p=0.231$. Similarly, as shown in Table 6, these correlations between number and spatial talk content types were generally non-significant. One exception is that parents with more instances of counting in the grocery task also tended to speak about deictics more frequently in the magnet board task with their children. Marginally significant associations were detected between parents' discussion of number symbols and the frequency of talk about shapes and spatial dimensions, as well as between instances of other abstract number talk and discussions of shapes. Among the utterance type codes (see Table 7), the frequency of statements about number and spatial content were not related as well. However, parents who asked more questions that involved numbers also tended to ask more spatial questions, $r=0.20, p=0.03$.

\section{Parent Time Diary Interviews}

As described in the methods, three measures of math input were provided by the time diaries: time in math activities during the day (i.e., math time from child time diary schedule), estimates of time in math activities aggregated across academic stimulation activities (i.e., total math time estimated), and sums of unique math activities that occurred (i.e., total number of number/spatial activities). During parents' reports of their child's schedule throughout the day in the time diaries, math activities were reported infrequently. Only $11 \%$ of parents reported directly engaging in any math activities on work days, and only $15 \%$ reported engaging in math activities on a non-work day. However, when explicitly asked about whether specific math activities occurred, almost all parents reported that at least one of these activities occurred on a work day and on a nonwork day ( $96 \%$ for both days). Descriptive statistics of time diary variables are shown in Table 5, including estimates of children's available time and parents' time working on each day. On parents' work days, parents worked an average of $5 \mathrm{~h}$ per day $(S D=4 \mathrm{~h})$, and children were awake and not in preschool $9.5 \mathrm{~h}$ a day $(S D=3.5 \mathrm{~h})$. On non-work days, children were awake and not at preschool for approximately $12.25 \mathrm{~h}$ a day $(S D=1.85 \mathrm{~h})$. As described above, reports of math-related time were highly skewed, and math time was considerably longer according to the summed durations of math activities that parents estimated at the end of the interviews compared to children's TD schedules. According to the academic stimulation activities durations, children spent on average 40 to $45 \mathrm{~min}$ in math activities on weekdays and over an hour in math activities on days when their parents were not working. When considering how much time children had available to spend in these activities (i.e., time awake and not in preschool), this corresponded to between $9 \%$ and $10 \%$ of time available during those days, compared to $1 \%$ of children's time available based on children's time diary schedules. Most parents reported about three number activities and one spatial activity on work and nonwork days.

Table 8 shows the intercorrelations of time and frequency variables from the full-time diary interviews across work days and non-work days. First, parents' reports of time in math activities from children's daily schedules were largely unrelated to other time diary measures. One exception to this pattern is that duration of math activities on work days, from the child time diary schedule and the academic stimulation activities, were moderately correlated. Within the academic stimulation

TABLE 6 | Pair-wise correlations among number and spatial utterance content codes.

\begin{tabular}{|c|c|c|c|c|c|c|c|c|c|c|}
\hline Math utterance content & 1 & 2 & 3 & 4 & 5 & 6 & 7 & 8 & 9 & 10 \\
\hline 1. Identifying number symbols & 1.00 & & & & & & & & & \\
\hline 2. Counting & 0.03 & 1.00 & & & & & & & & \\
\hline 3. Labeling set sizes & 0.11 & $0.38^{\star \star \star}$ & 1.00 & & & & & & & \\
\hline 4. Arithmetic & 0.09 & $0.33^{\star \star \star}$ & $0.35^{\star \star \star}$ & 1.00 & & & & & & \\
\hline 5. Other abstract number talk & $0.26^{\star \star}$ & $0.26^{\star \star}$ & 0.08 & 0.13 & 1.00 & & & & & \\
\hline 6. Shapes & $0.17^{\dagger}$ & 0.08 & 0.003 & -0.04 & $0.17^{\dagger}$ & 1.00 & & & & \\
\hline 7. Locations, directions and orientations & 0.12 & 0.05 & -0.01 & -0.04 & 0.09 & $0.39^{\star \star \star}$ & 1.00 & & & \\
\hline 8. Features and properties & 0.09 & -0.05 & 0.04 & -0.09 & -0.02 & $0.23^{*}$ & $0.64^{\star * \star}$ & 1.00 & & \\
\hline 9. Deictics & 0.10 & $0.20^{*}$ & 0.10 & 0.02 & 0.12 & $0.40^{\star \star \star}$ & $0.43^{\star \star \star}$ & 0.08 & 1.00 & \\
\hline 10. Spatial dimensions & $0.18^{\dagger}$ & -0.03 & -0.07 & -0.01 & 0.08 & $0.50^{\star \star \star}$ & $0.38^{\star \star \star}$ & $0.23^{\star}$ & $0.31^{\star \star \star}$ & 1.00 \\
\hline 11. Continuous amount & 0.09 & -0.08 & 0.02 & -0.06 & 0.09 & $0.23^{\star}$ & $0.58^{\star \star \star}$ & $0.40^{\star \star \star}$ & 0.12 & $0.34^{\star \star \star}$ \\
\hline
\end{tabular}

${ }^{\dagger} p<0.10,{ }^{*} p<0.05,{ }^{* *} p<0.01,{ }^{* * *} p<0.001$. 
TABLE 7 | Pair-wise correlations among math utterance type codes.

\begin{tabular}{llll}
\hline Math utterance type & $\mathbf{1}$ & $\mathbf{2}$ & $\mathbf{3}$ \\
\hline 1. Number statements & 1.00 & & \\
2. Number questions & $0.53^{\star \star *}$ & 1.00 & \\
3. Spatial statement & 0.06 & 0.01 & 1.00 \\
4. Spatial questions & 0.07 & $0.20^{\star}$ & $0.29^{* *}$ \\
${ }^{*} p<0.05,{ }^{* *} p<0.01,{ }^{* * *} p<0.001$. & &
\end{tabular}

measure, parents' estimates of children's time in math activities (i.e., prompted responses) were highly correlated with frequency counts of number, spatial, and overall math activities on those same days. Additionally, estimated time in math activities were significantly correlated across days, as were counts of number activities and the composite measure of all math activity time. In other words, parents who reported engaging in more number activities or for more math activity time on work days also reported more number activities or more math activity time on non-work days. However, no significant association was evident between the number of spatial activities on work days and non-work days. Overall, parents who reported more number activities also reported significantly more spatial activities, although this association was only marginally significant for work days.

\section{Intercorrelations Across Parental Math Support Assessments}

We then examined the degree to which measures of parental support for early math skills were consistent across modalities (see Table $\mathbf{9}$ for math time, Table $\mathbf{1 0}$ for number support, and Table 11 for spatial support). First, in examining total time in math activities from the child's time diary schedule, few significant correlations were seen between any observed measures of number or spatial talk or the frequency of number or spatial activities from the survey with daily time in math activities (see Table 9). Minutes of math time on non-work days was marginally correlated with number talk about arithmetic, but all other correlations with these other data sources were nonsignificant. In contrast, the time estimates from the academic stimulation activities reports, specifically math activity time on non-work days, were significantly correlated with observed number (identifying number symbol) and spatial (continuous amount) talk, as well as both number and spatial activity composites on the survey. However, estimated time in math activities on a work day was unrelated to observational or survey measures of number or spatial talk.

We then examined interrelations among multiple data sources of parental support for numeracy skills (see Table 10), including observed number talk content and type, the number activities scale, and frequencies of number activities on work and non-work days from the academic stimulation activities interview. The questionnaire measure of home number activities was significantly and positively related with the frequency of arithmetic talk from the semi-structured grocery task. In contrast, the questionnaire measure was unrelated to the remaining number utterances content codes involving number symbols, counting, labeling set sizes, and other abstract number talk. In regard to number talk utterance types, neither number statements nor questions were significantly related to questionnaire responses of number activities at home. The questionnaire measure of home number activities was also positively associated with the count of number activities from the time diary, particularly for work day reports of number activities $(r=0.32)$. Additionally, time diary reports of number activities were marginally associated with several number talk measures, including instances of number activities on non-work days and counting and number statements, whereas number activities on a work day was marginally related to parents' other abstract number talk. Overall, total number utterances were also not associated with the survey measure of number activities, $r(111)=0.14, p=0.140$, parents' reported number activities on a work day, $r(90)=0.16, p=0.121$, or parents' reported number activities on a non-work day, $r(88)=0.18, p=0.086$, although the latter did reach trend-level significance.

Finally, we conducted these analyses with parents' survey reports of spatial activities, spatial talk, and summed spatial activities reported on time diaries (see Table 11). As with number talk, spatial talk observational codes, including spatial content and spatial utterance types, were largely unrelated to the frequency of spatial activities reported on the parent survey. Likewise, total spatial utterances were unrelated to parent reports of spatial activities in the survey, $r(109)=-0.01, p=0.94$. One notable exception to this trend was the frequency of spatial utterances discussing features and properties, which was negatively correlated with the frequency of spatial activities, such that parents who reported more spatial activities actually used these terms less often. Parents' reports of spatial activities on the survey were correlated with time diary reports from nonwork days but not from work days, the opposite pattern of results as observed for number activities. Last, we examined associations between observed spatial talk and time diary reports of spatial activities. The frequency of spatial activities reported on work days was not significantly related to the frequency of any categories of spatial content, or spatial statements or questions, as well as overall spatial talk, $r(101)=0.02, p=0.86$. Spatial activities reported on non-work days were marginally associated with the frequency of utterances discussing continuous amount but were unrelated to all other categories of spatial talk, including overall spatial talk, $r(99)=0.12, p=0.219$.

\section{DISCUSSION}

Within this small but socioeconomically diverse sample, we see both wide individual differences in parental support of early number and spatial skills within each assessment method, as well as promising convergence of parents' support for early math across data sources.

\section{Within-Method Variability Parent Survey Responses}

In these analyses, we attempted to differentiate between number and spatial activities in parent surveys. Parents reported engaging 
TABLE 8 | Pair-wise correlations among reports of time in math activities and counts of numeracy, spatial, and overall math activities from time diary interviews.

\begin{tabular}{|c|c|c|c|c|c|c|c|c|c|}
\hline & 1 & 2 & 3 & 4 & 5 & 6 & 7 & 8 & 9 \\
\hline 1. Minutes of math time, work day: Child TD schedule & 1.00 & & & & & & & & \\
\hline 2. Minutes of math time, non-work day: Child TD schedule & -0.07 & 1.00 & & & & & & & \\
\hline 3. Minutes of math time, work day: Acad. stim. activities & $0.26^{\star \star}$ & 0.16 & 1.00 & & & & & & \\
\hline 4. Minutes of math time, non-work day: Acad. stim. activities & -0.06 & 0.06 & $0.25^{\star}$ & 1.00 & & & & & \\
\hline 5. Work day numeracy activities & 0.13 & -0.04 & $0.49^{\star \star \star}$ & 0.15 & 1.00 & & & & \\
\hline 6. Non-work day numeracy activities & $-0.20^{\dagger}$ & 0.12 & $0.19^{\dagger}$ & $0.42^{\star \star \star}$ & $0.28^{\star \star}$ & 1.00 & & & \\
\hline 7. Work day spatial activities & 0.14 & 0.04 & $0.50^{\star \star \star}$ & 0.14 & $0.18^{\dagger}$ & 0.16 & 1.00 & & \\
\hline 8. Non-work day spatial activities & -0.04 & 0.01 & 0.07 & $0.47^{\star \star \star}$ & 0.01 & $0.37^{\star \star \star}$ & 0.11 & 1.00 & \\
\hline 9. Work day math activities & 0.15 & -0.02 & $0.60^{\star \star \star}$ & 0.18 & $0.92^{\star \star \star}$ & $0.30^{\star \star}$ & $0.56^{\star \star \star}$ & 0.07 & 1.00 \\
\hline 10. Non-work day math activities & $-0.18^{\dagger}$ & 0.11 & 0.18 & $0.51^{\star \star \star}$ & $0.24^{\star}$ & $0.95^{\star \star \star}$ & $0.17^{\dagger}$ & $0.64^{\star \star \star}$ & $0.28^{\star}$ \\
\hline
\end{tabular}

${ }^{\dagger} p<0.10,{ }^{*} p<0.05,{ }^{* *} p<0.01,{ }^{* * *} p<0.001$.

TABLE 9 | Associations among number and spatial talk content from the semi-structured observations, home number and spatial activities scale, and time in math activities reported on work and non-work days from the time diary interview.

\begin{tabular}{|c|c|c|c|c|}
\hline & $\begin{array}{c}\text { Minutes of math } \\
\text { time, work day: Child } \\
\text { TD schedule }\end{array}$ & $\begin{array}{l}\text { Minutes of math } \\
\text { time, non-work day: } \\
\text { Child TD schedule }\end{array}$ & $\begin{array}{l}\text { Minutes of math } \\
\text { time, work day: } \\
\text { Acad. stim. activities }\end{array}$ & $\begin{array}{c}\text { Minutes of math } \\
\text { time, non-work day: } \\
\text { Acad. stim. activities }\end{array}$ \\
\hline Overall number talk & -0.11 & 0.09 & -0.06 & 0.05 \\
\hline \multicolumn{5}{|l|}{ Number talk content } \\
\hline Identifying number symbols & 0.10 & -0.02 & 0.06 & $0.22^{\star}$ \\
\hline Counting & -0.09 & 0.03 & -0.08 & -0.06 \\
\hline Labeling set sizes & -0.15 & 0.07 & -0.09 & -0.03 \\
\hline Arithmetic & -0.03 & $0.19^{\dagger}$ & 0.03 & -0.03 \\
\hline Other abstract math talk & -0.13 & 0.07 & 0.04 & 0.004 \\
\hline \multicolumn{5}{|l|}{ Number talk type } \\
\hline Statements & -0.07 & 0.07 & -0.004 & 0.04 \\
\hline Questions & -0.09 & 0.10 & -0.08 & 0.03 \\
\hline Number activities scale & 0.10 & 0.08 & 0.16 & $0.22^{\star}$ \\
\hline Overall spatial talk & -0.001 & -0.03 & 0.02 & 0.11 \\
\hline \multicolumn{5}{|l|}{ Spatial talk content } \\
\hline Shapes & -0.06 & -0.08 & -0.07 & 0.11 \\
\hline Locations, directions and orientations & 0.0004 & -0.04 & -0.01 & 0.06 \\
\hline Features and properties & 0.10 & -0.02 & 0.03 & -0.04 \\
\hline Deictics & -0.05 & -0.11 & -0.12 & -0.08 \\
\hline Spatial dimensions & -0.05 & -0.02 & 0.07 & 0.08 \\
\hline Continuous amount & -0.01 & 0.07 & 0.11 & $0.21^{*}$ \\
\hline \multicolumn{5}{|l|}{ Spatial talk type } \\
\hline Statements & -0.07 & -0.09 & -0.02 & 0.05 \\
\hline Questions & 0.03 & 0.01 & -0.01 & 0.09 \\
\hline Spatial activities scale & 0.01 & 0.06 & 0.07 & $0.34^{\star \star \star}$ \\
\hline
\end{tabular}

${ }^{*} p<0.05,{ }^{* *} p<0.001$.

in number-related activities several times per month and spatial activities weekly. Past studies have differentiated between parents' numerical and spatial support (Dearing et al., 2012; Hart et al., 2016; Purpura et al., 2020; Zippert and Rittle-Johnson, 2020) but found different relations between them. In some studies, reports of number and spatial activities were positively correlated (Hart et al., 2016; Zippert and Rittle-Johnson, 2020), others found no correlation (Purpura et al., 2020) or did not present this correlation (Dearing et al., 2012). In the present study, these subdimensions of math support were moderately correlated. On the one hand, it is worth noting that the LeFevre et al.
(2009) scale was designed to broadly address possible mathrelated activities and not to assess spatial activities specifically. It is possible that with a more extensive, theoretically driven set of spatial items, spatial and numerical support may emerge as more distinct constructs. Additionally, when recalling activities over the prior month, parents' endorsements of engaging in a wide range of math activities may be susceptible to response biases and these may be shared across number and spatial activities. Parents' reports of the prior day's number and spatial activities differed in frequency and were also much more weakly correlated in the time diary data (see discussion below). Thus, 
TABLE 10 | Associations among number talk content from the semi-structured observations, home number activities scale, and number activities reported on work and non-work days from the time diary interview.

\begin{tabular}{lccc}
\hline & $\begin{array}{c}\text { Number } \\
\text { activities } \\
\text { scale }\end{array}$ & $\begin{array}{c}\text { Work day } \\
\text { number } \\
\text { activities }\end{array}$ & $\begin{array}{c}\text { Non-work day } \\
\text { number } \\
\text { activities }\end{array}$ \\
\hline Overall number talk & 0.14 & 0.16 & $0.18^{\dagger}$ \\
Number talk content & -0.01 & 0.15 & 0.08 \\
Identifying number symbols & 0.08 & -0.05 & $0.20^{\dagger}$ \\
Counting & 0.12 & 0.13 & 0.14 \\
Labeling set sizes & $0.20^{\star}$ & 0.14 & 0.06 \\
Arithmetic & 0.05 & $0.19^{\dagger}$ & 0.10 \\
Other abstract math talk & & & $0.19^{\dagger}$ \\
Number talk type & 0.13 & 0.13 & 0.07 \\
Statements & 0.13 & $0.32^{* *}$ & 0.15 \\
Questions & - & & \\
Number activities scale & & &
\end{tabular}

${ }^{\dagger} p<0.10,{ }^{*} p<0.05,{ }^{* *} p<0.01$.

TABLE 11 | Associations among spatial talk content from the semi-structured observations, home spatial activities scale, and spatial activities reported on work and non-work days from the time diary interview.

\begin{tabular}{lccc}
\hline & $\begin{array}{c}\text { Spatial } \\
\text { activities } \\
\text { scale }\end{array}$ & $\begin{array}{c}\text { Work day } \\
\text { spatial } \\
\text { activities }\end{array}$ & $\begin{array}{c}\text { Non-work day } \\
\text { spatial } \\
\text { activities }\end{array}$ \\
\hline Overall spatial talk & -0.01 & 0.02 & 0.12 \\
Spatial talk content & 0.02 & -0.08 & 0.05 \\
Shapes & -0.10 & 0.02 & 0.16 \\
Locations, directions and orientations & $-0.21^{*}$ & 0.05 & -0.03 \\
Features and properties & 0.11 & -0.02 & -0.04 \\
Deictics & -0.09 & -0.10 & 0.03 \\
Spatial dimensions & -0.03 & 0.04 & $0.20^{\dagger}$ \\
Continuous amount & & & 0.01 \\
Spatial talk type & -0.14 & -0.05 & 0.16 \\
Statements & 0.11 & 0.02 & $0.19^{*}$ \\
Questions & - & 0.15 & \\
Spatial activities scale & & & \\
\hline
\end{tabular}

${ }^{\dagger} p<0.10,{ }^{*} p<0.05$.

more work developing and validating measures of math support that differentiate spatial- and number-related activities is needed to explore these questions further.

\section{Time Diaries}

During parents' minute-by-minute recounting of activities during the prior day, math-related activities were infrequently reported. Specifically, approximately $1 \%$ of children's available time while not in preschool or sleeping was reported as engaged in a math-related activity by parents completing the time diary interview. However, subsequent probing during the interview about specific math-related activities increased the types and duration of children's exposure to math activities that the time diary interviews did not provide. When asked about daily math activities during the previous day, average sums of number activities were similar across work and non-work days, with a similar pattern reported for spatial activities. However, unlike the survey reports, the time diary reports revealed much less engagement in spatial activities than number activities for both work and non-work days, which is more consistent with previous findings using parent surveys (Zippert and Rittle-Johnson, 2020; Zippert et al., 2020). These differences should be interpreted with caution, however, as parents were asked about fewer spatial activities than number activities, resulting in a lower maximum value (4 spatial activities compared to 21 number activities).

Examination of correlations with each assessment revealed that although engagement in number activities was somewhat consistent across work and non-work days, parent reports of spatial activities was unrelated and thus inconsistent across work and non-work days. One possible explanation is that spatial activities such as puzzles or block play take more time than number activities such as counting or playing with number fridge magnets, and thus, parents are more likely to engage in spatial activities with children on non-work days than work days. It should also be noted that engagement in a variety of mathrelated activities was more likely to occur on non-work days, where the correlation between number and spatial activities was much higher than for work days. Thus, parental employment patterns appear substantively linked to parental support for early math. Notably, the proportion of available time devoted to math activities was comparable across work and non-work days, but families had more opportunities for these activities on non-work days. More research is needed to determine how variation in parents' employment experiences, such as non-standard work hours, changing weekly work schedules, working 6 or 7 days per week, etc., impacts children's exposure to math-related activities at home.

\section{Observations of Parent Math Talk}

The present study also examined parent talk during two semistructured tasks that were designed to elicit number-related talk (grocery task) and spatial talk (magnet board puzzle task). Within each task, parents displayed considerable variability in the frequency and types of math content that they discussed with their child. For example, within an 8-min grocery task, parents provided an average of 14 utterances involving labeling sets with about two instances each of counting and identifying number symbols. Likewise, in the magnet task, parents spoke an average of 11-18 utterances for spatial concepts such as locations, directions and orientations, continuous amount, deictics, and shapes. It is notable that spatial talk occurred much more frequently in the magnet board puzzle task than did number talk in the grocery task. These differences could be due to differences in task design, such that the puzzle task had an end goal that required a solution, whereas the grocery task was much more open-ended. In other words, parents may have used spatial talk more given that they needed to engage with the materials spatially, but in the grocery task parents and children were not necessarily instructed to pretend shop, buy specific quantities of certain items, or discuss and exchange money. Parents' number talk during the grocery task could be lower thus if some parents engaged in other types of interactions around groceries and shopping (see VandermaasPeeler et al., 2009, for an example). 
In addition, within each task, most of the number talk codes and spatial talk codes were intercorrelated, although we did not examine if number or spatial talk codes were correlated across these very different tasks. Among the number talk codes, however, some correlations were low or non-significant, suggesting that number talk may not be a single unitary construct. Instead, future research should aim to capture and differentiate between these distinct types of number talk (e.g., counting compared to identifying numerals). Additionally, few correlations reached statistical significance when examining the math content of parent talk across tasks. In other words, parents who provided high frequencies of number talk did not necessarily provide high levels of spatial talk, and vice versa. Importantly, number talk and spatial talk were measured during separate activities, each designed to elicit a high frequency of the respective type of talk. In contrast, parents' conversational style across the semi-structured observational tasks was modestly consistent, such that number and spatial questions were significantly and positively correlated across tasks. Although statements and questions within each domain of math talk were modestly correlated, one direction for future research is to explore whether these distinct aspects of number and spatial talk differentially relate to children's development in these areas. An additional future research direction is to determine the extent to which these math discussions reflect the parent's appraisal of their child's skills rather than a parent conversational style, such that parents provide more questions if they expect the child can answer them and more statements if they are trying to teach foundational concepts.

\section{Triangulating Across Measures of Parental Support for Early Math Development}

Overall, measures of parental support for early math obtained from parent reports (i.e., surveys and time diaries) demonstrated more convergence than either parent report method with observed math talk codes. This pattern was also consistent across measures of number and spatial activities. When examining the parent report measures, it appears that parents' survey responses about their monthly number-related activities were driven by recollections of activities and interactions during work days. Even though parents varied widely in their hours worked per week, the work day number activities were apparently more salient as they responded to questionnaire items about the activities during the prior month. In contrast, survey reports of monthly spatial activities were somewhat more related to non-work day than work day time diary reports, although the low incidence of spatial activities in the time diary data likely constrained these associations.

Very few significant associations between observed math talk during semi-structured observations and parent reports of math-related activities were detected, and this generally null finding held across number and spatial talk. Instances of discordance across these multi-method assessments may reflect measurement error but also authentic differences in the contexts that each metric assessed (i.e., math talk during semi-structured observations, daily math activities, and monthly engagement in math activities). Parental support of early math skills may be a multidimensional construct, such that each assessment modality is identifying related and distinct features of this construct. For example, math talk may identify best case scenarios for parental math support while parental report may index opportunities for exposure to math content, regardless of the actual occurrence and qualitative features of math support. In addition, math talk likely also reflects a child's interest in the subject matter at the very moment of observation while parental report may signify more sustained, long-term interests in activities. Future research should utilize multivariate approaches such as cluster analyses and mixture modeling to examine the combinations and patterns in ways that parents support their young children's math learning. For example, recent work suggests that although parental number talk is more common during math-related activities, the strength of this association varies, such that some parents are more able to integrate discussion of number concepts into activities that are not related to math than other parents (Thippana et al., 2020). As such, there may be parents who engage in extensive math talk but do not necessarily report a high number of math activities. By simply examining the correlations across measures, we may overlook these theoretically interesting subgroups of parents.

The divergence across methodologies highlighted here also demonstrates the need for intentional selection of measures of math support in future studies. In particular, we suggest that future research includes multiple metrics of math support in order to capture these various dimensions of parents' support of early math skills, including potential interactions between dimensions.

\section{Limitations}

The present study examined rich, in-depth measurement of parental support of early math skills across data sources and methods. This intensive, novel examination offers new insights into how parents are reporting about their math-related home activities. Given the exploratory nature of this investigation, future research is needed to replicate and extend the current findings. In addition, although we heavily focused our summary of results on general patterns of associations, rather than specific intercorrelations, caution is warranted when interpreting the findings given the number of statistical tests performed. Future work should include larger samples and examine the concurrent and predictive validity of these assessments with children's early numeracy and spatial skills. Similarly, more work exploring reliability of these measures, specifically regarding test-retest reliability for observational and time diary measures, would extend these findings. In addition, it should be noted that the majority of participants were recruited from preschool centers, and thus, it is unclear whether parents of 4-yearold's who are not enrolled in early learning programs would display similar frequencies of home math activities or math talk. Furthermore, the cross-sectional, correlational design precludes us from understanding how children's characteristics influence what parents do, why parents differ in what they do, and how daily activities or conversational patterns may change over time as children age and enter formal schooling. 


\section{CONCLUSION}

In conclusion, current evidence of triangulation across multimethod approaches holds great promise for future larger scale studies of early math development. Statistical methods such as latent variable modeling could combine these multiple methods and data sources into a broader, more comprehensive latent construct of home practices to predict children's early math skills. A latent variable approach would address the mono-operation bias occurring in many studies of early math by estimating and partialing out measurement error from the prediction model. Given parents' relatively infrequent efforts to discuss math concepts or engage in math-related activities at home, this multi-method approach holds great promise for furthering our understanding of when and how parents support early math skills with their preschool-aged children.

\section{DATA AVAILABILITY STATEMENT}

Data are drawn from an ongoing longitudinal study, and we have arranged with our funder to release the data at the completion of the study.

\section{ETHICS STATEMENT}

The studies involving human participants were reviewed and approved by University of Pittsburgh Institutional Review Board. Written informed consent to participate in this study was provided by the participants' legal guardian/next of kin.

\section{AUTHOR CONTRIBUTIONS}

$\mathrm{HB}, \mathrm{LE}, \mathrm{MN}, \mathrm{EV}-\mathrm{D}$, and ML contributed to the conception and design of the study. LE and MN organized the database.

\section{REFERENCES}

Ard, L. M., and Beverly, B. L. (2004). Preschool word learning during joint book reading: effect of adult questions and comments. Commun. Disord. Q. 26, 17-28. doi: 10.1177/15257401040260010101

Blevins-Knabe, B., and Musun-Miller, L. (1996). Number use at home by children and their parents and its relationship to early mathematical performance. Early Dev. Parent. 5, 35-45. doi: 10.1002/(sici)1099-0917(199603)5:1<35::aidedp113>3.0.co;2-0

Cannon, J., and Ginsburg, H. P. (2008). "Doing the Math": maternal beliefs about early mathematics versus language learning. Early Educ. Dev. 19, 238-260. doi: 10.1080/10409280801963913

Casasola, M., Wei, W. S., Suh, D. D., Donskoy, P., and Ransom, A. (2020). Children's exposure to spatial language promotes their spatial thinking. J. Exper. Psychol. Gen. 149, 1116-1136. doi: 10.1037/xge0000699

Casey, B. M., Lombardi, C. M., Thomson, D., Nguyen, H. N., Paz, M., Theriault, C. A., et al. (2018). Maternal support of children's early numerical concept learningpredicts preschool and first-grade math achievement. Child Dev. 89, 156-173. doi: $10.1111 /$ cdev.12676

Chorney, J. M., McMurty, C. M., Chambers, C. T., and Bakeman, R. (2015). Developing and modifying behavioral coding schemes in pediatric psychology: a practical guide. J. Pediatr. Psychol. 40, 154-164. doi: 10.1093/jpepsy/jsu099
LE performed the statistical descriptive analyses. SD and LB conducted reliability analyses for coded data. HB wrote the first draft of the manuscript. LE, SD, LB, and ML wrote sections of the manuscript. All authors contributed to the manuscript revision, read and approved the submitted version.

\section{FUNDING}

Primary funding for this research was provided by the Eunice Kennedy Shriver National Institute of Child Health and Human Development (1 R01 HD093689-01A1) to HB, ML, and EV-D. This project also benefited from intellectual synergies stemming from several related studies funded by the National Science Foundation (Award Number: 1920545), an internal award from the Learning Research and Development Center at the University of Pittsburgh, and a Scholar Award from the James S. McDonnell Foundation to ML.

\section{ACKNOWLEDGMENTS}

We would like to thank the editor and the reviewers for their comments. Any opinions, findings, and conclusions or recommendations expressed in this material are those of the authors and does not necessarily reflect the views of the NICHD, the NSF, the LRDC, the James S. McDonnell Foundation, or the reviewers. We thank our project team for all their assistance with data collection and coding. A special thank you is also extended to the community partners that assisted our recruitment efforts and the children and families who participated in the Parents Promoting Early Learning (PPEL) project. APC charges for this article were fully paid by the University Library System, University of Pittsburgh.

Cook, T. D., and Campbell, D. T. (1979). Quasi-Experimentation: Design and Analysis Issues for Field Settings. Chicago: Rand McNally College Publishing.

Cortes, K. E., Goodman, J. S., and Nomi, T. (2015). Intensive math instruction and educational attainment long-run impacts of double-dose algebra. J. Hum. Resour. 50, 108-158. doi: 10.1353/jhr.2015.0004

Dearing, E., Casey, B. M., Ganley, C. M., Tillinger, M., Laski, E., and Montecillo, C. (2012). Young girls' arithmetic and spatial skills: the distal and proximal roles of family socioeconomics and home learning experiences. Early Childh. Res. Q. 27, 458-470. doi: 10.1016/j.ecresq.2012.01.002

DeFlorio, L., and Beliakoff, A. (2015). Socioeconomic status and preschoolers' mathematical knowledge: the contribution of home activities and parent beliefs. Early Educ. Dev. 26, 319-341. doi: 10.1080/10409289.2015.96 8239

Elliott, L., and Bachman, H. J. (2018). How do parents foster young children's math skills? Child Dev. Perspect. 12, 16-21. doi: 10.1111/cdep.12249

Elliott, L., Bachman, H. J., and Henry, D. (2020). Why and how do parents promote math learning with their young children? Parent. Sci. Pract. 20, 108-140. doi: $10.1080 / 15295192.2019 .1694830$

Elliott, L. E., Braham, E. J., and Libertus, M. E. (2017). Understanding sources of individual variability in parents' number talk with young children. J. Exp. Child Psychol. 159, 1-15. doi: 10.1016/j.jecp.2017.01.011 
Ferrara, K., Hirsh-Pasek, K., Newcombe, N. S., Golinkoff, R. M., and Lam, W. S. (2011). Block talk: spatial language during block play. Mind Brain Educ. 5, 143-151. doi: 10.1111/j.1751-228x.2011.01122.x

Fiorini, M., and Keane, M. P. (2014). How the allocation of children's time affects cognitive and noncognitive development. J. Lab. Econ. 32, 787-836. doi: 10. 1086/677232

Ginsburg, H. P., Lee, J. S., and Boyd, J. S. (2008). Mathematics education for young children: what it is and how to promote it. SRCD Soc. Policy Rep. 22, 1-23. doi: 10.1002/j.2379-3988.2008.tb00054.x

Gunderson, E. A., and Levine, S. C. (2011). Some types of parent number talk count more than others: relations between parents' input and children's cardinalnumber knowledge. Dev. Sci. 14, 1021-1032. doi: 10.1111/j.1467-7687.2011. 01050.x

Gunthert, K., and Wenze, S. (2011). "Time diary methods," in Handbook of Research Methods for Studying Daily Life, eds M. R. Mehl and T. S. Conner (New York, NY: The Guilford Press).

Hallgren, K. A. (2012). Computing inter-rater reliability for observational data: an overview and tutorial. Tutor Q. Methods Psychol. 8, 23-34. doi: 10.20982/tqmp. 08.1.p023

Hanushek, E. A., and Woessman, L. (2015). "Skills, mobility, and growth," in Proceedings of the Ninth Biennial Federal Reserve System Community Development Research Conference, Washington, DC.

Hart, S. A., Ganley, C. M., and Purpura, D. J. (2016). Understanding the home math environment and its role in predicting parent report of children's math skills. PLoS One 11:e0168227. doi: 10.1371/journal.pone.0168227

Heath, L. (2015). "Triangulation," in The International Encyclopedia of Social and Behavioral Sciences, eds N. J. Smelser and P. B. Baltes, 2nd Edn, London: Elsevier Press.

Ho, A., Lee, J., Wood, E., Kassies, S., and Heinbuck, C. (2018). Tap, swipe, and build: parental spatial input during $\mathrm{iPad}^{\circledR}$ and toy play. Infant Child Dev. 27:e2061. doi: 10.1002/icd.2061

Hofferth, S. L., and Sandberg, J. F. (2001). How American children spend their time. J. Marriage Fam. 63, 295-308.

Huntsinger, C. S., Jose, P. E., and Luo, Z. (2016). Parental facilitation of early mathematics and reading skills and knowledge through encouragement of home-based activities. Early Childh. Res. Q. 37, 1-15. doi: 10.1016/j.ecresq.2016. 02.005

Juster, F. T., and Stafford, F. P. (1985). Time, Goods and Well-Being. Ann Arbor, MI: University of Michigan.

Kaufman, A. S., Kaufman, J. C., Liu, X., and Johnson, C. K. (2008). How do educational attainment and gender relate to fluid intelligence, crystalized intelligence, and academic skills at ages 22-90 years? Archiv. Clin. Neuropsychol. 24, 153-163. doi: 10.1093/arclin/acp015

Kleemans, T., Peeters, M., Segers, E., and Verhoeven, L. (2012). Child and home predictors of early numeracy skills in kindergarten. Early Childh. Res. Q. 27, 471-477. doi: 10.1016/j.ecresq.2011.12.004

Klibanoff, R. S., Levine, S. C., Huttenlocher, J., Vasilyeva, M., and Hedges, L. V. (2006). Preschool children's mathematical knowledge: the effect of teacher "math talk. Dev. Psychol. 42, 59-69. doi: 10.1037/0012-1649.42.1.59

Kotila, L. E., Schoppe-Sullivan, S. J., and Kamp Dush, C. M. (2013). Time in parenting activities in dual-earner families at the transition to parenthood. Fam. Relat. 62, 795-807. doi: 10.1111/fare.12037

Lee, J., Hodgins, S., and Wood, E. (2019). "Spatial learning and play with technology: how parental spatial talk differs across contexts," in Mathematical Learning and Cognition in Early Childhood, eds K. Robinson, H. Osana, and D. Kotsopoulos (Cham: Springer), 23-38. doi: 10.1007/978-3-030-12895-1_3

Lee, Y., Hofferth, S. L., Flood, S. M., and Fisher, K. (2016). Reliability, validity, and variability of the subjective well-being questions in the 2010 American Time Use Survey. Soc. Indic. Res. 126, 1355-1373. doi: 10.1007/s11205-0150923-8

LeFevre, J., Polyzoi, E., Skwarchuk, S., Fast, L., and Sowinski, C. (2010). Do home numeracy and literacy practices of Greek and Canadian parents predict the numeracy skills of kindergarten children? Intern. J. Early Years Educ. 18, 55-70. doi: 10.1080/09669761003693926

LeFevre, J., Skwarchuk, S. L., Smith-Chant, B. L., Fast, L., Kamawar, D., and Bisanz, J. (2009). Home numeracy experiences and children's math performance in the early school years. Can. J. Behav. Sci. 41:55. doi: 10.1037/a0014532
Levine, S. C., Suriyakham, L. W., Rowe, M. L., Huttenlocher, J., and Gunderson, E. A. (2010). What counts in the development of young children's number knowledge? Dev. Psychol. 46, 1309-1319. doi: 10.1037/a0019671

Leyva, D., Tamis-LeMonda, C., Yoshikawa, H., Jimenez-Robbins, C., and Malachowski, L. (2017). Grocery games: how ethnically diverse low-income mothers support children's mathematics and literacy. Early Childh. Res. Q. 40, 63-76. doi: 10.1016/j.ecresq.2017.01.001

Manolitsis, G., Georgiou, G. K., and Tziraki, N. (2013). Examining the effects of home literacy and numeracy environment on early reading and math acquisition. Early Childh. Res. Q. 28, 692-703. doi: 10.1016/j.ecresq.2013.05.004

Mathison, S. (1988). Why triangulate? Educ. Res. 17, 13-17. doi: 10.3102/ 0013189x017002013

McHugh, M. L. (2012). Interrater reliability: the kappa statistic. Biochem. Med. Biochem. Med. 22, 276-282. doi: 10.11613/bm.2012.031

Mermelshtine, R. (2017). Parent-child learning interactions: a review of the literature on scaffolding. Br. J. Educ. Psychol. 87, 241-254. doi: 10.1111/bjep. 12147

Missall, K., Hojnoski, R. L., Caskie, G. I. L., and Repasky, P. (2014). Home numeracy environments of preschoolers: examining relations among mathematical activities, parent mathematical beliefs, and early mathematical skills. Early Educ. Dev. 26, 356-376. doi: 10.1080/10409289.2015.968243

Missall, K. N., Hojnoski, R. L., and Moreano, G. (2017). Parent-child mathematical interactions: examining self-report and direct observation. Early Child Dev. Care 187, 1896-1908. doi: 10.1080/03004430.2016.1193731

Murmane, R. J., Willett, J. B., and Duhaldeborde, Y. (2000). How important are the cognitive skills of teenagers in predicting subsequent earnings? J. Policy Analys. Manag. 19, 547-568. doi: 10.1002/1520-6688(200023)19:4<547::aid-pam2>3. $0 . c 0 ; 2-\#$

Mutaf Yıldız, B., Sasanguie, D., De Smedt, B., and Reynvoet, B. (2018). Frequency of home numeracy activities is differentially related to basic number processing and calculation skills in kindergartners. Front. Psychol. 9:340. doi: 10.3389/ fpsyg.2018.00340

National Research Council (2009). "Mathematics learning in early childhood: paths toward excellence and equity. committee on early childhood mathematics," in Center for Education, Division of Behavioral and Social Sciences and Education, eds C. T. Cross, T. A. Woods, and H. Schweingruber (Washington, DC: The National Academies Press).

Nesteruk, O., and Garrison, M. E. B. (2005). An exploratory study of the relationship between family daily hassles and family coping and managing strategies. Fam. Consum. Sci. Res. J. 34, 140-152. doi: 10.1177/ $1077727 \times 05280667$

Niklas, F., and Schneider, W. (2014). Casting the die before the die is cast: the importance of the home numeracy environment for preschool children. Eur. J. Psychol. Educ. 29, 327-345. doi: 10.1007/s10212-013-0201-6

Pan, B. A., Rowe, M. L., Spier, E., and Tamis-LeMonda, C. (2004). Measuring productive vocabulary of toddlers in low-income families: concurrent and predictive validity of three sources of data. J. Child Lang. 31, 587-608. doi: $10.1017 / \mathrm{s} 0305000904006270$

Parsons, S., and Bynner, J. (2005). Does Numeracy Matter More?. London: National Research and Development Centre for Adult Literacy and Numeracy.

Phipps, P. A., and Vernon, M. K. (2009). "Twenty-four hours: an overview of the recall diary method and data quality in the American time use survey," in Calendar and Time Diary: Methods in Life Course Research, eds R. F. Belli, F. P. Stafford and D. F. Alwin (Thousand Oaks, CA: SAGE Publications, Inc).

Polinsky, N., Perez, J., Grehl, M., and McCrink, K. (2017). Encouraging spatial talk: using children's museums to bolster spatial reasoning. Mind Brain Educ. 11, 144-152. doi: $10.1111 / \mathrm{mbe} .12145$

Price, J. (2010). The Effect of Parental Time Investments: Evidence from Natural Within-Family Variation. Provo, UT: Brigham Young University.

Pruden, S. M., Levin, S. C., and Huttenlocher, J. (2011). Children's spatial thinking: does talk about the spatial world matter? Dev. Sci. 14, 1417-1430. doi: 10.1111/ j.1467-7687.2011.01088.x

Purpura, D. J., King, Y. A., Rolan, E., Hornburg, C. B., Schmitt, S. A., Hart, S. A., et al. (2020). Examining the factor structure of the home mathematics environment to delineate its role in predicting preschool numeracy, mathematical language, and spatial skills. Front. Psychol. 11:1925. doi: 10.3389/fpsyg.2020.01925 
Ramani, G. B., Rowe, M. L., Eason, S. H., and Leech, K. A. (2015). Math talk during informal learning activities in head start families. Cogn. Dev. 35, 15-33. doi: 10.1016/j.cogdev.2014.11.002

Reynolds, E., Vernon-Feagans, L., Bratsch-Hines, M., Baker, C. E., and Family Life Project Key Investigators (2019). Mothers' and fathers' language input from 6 to 36 months in rural two-parent-families: relations to children's kindergarten achievement. Early Childh. Res. Q. 47, 385-395. doi: 10.1016/j.ecresq.2018.09.002

Ritchie, S. J., and Bates, T. C. (2013). Enduring links from childhood mathematics and reading achievement to adult socioeconomic status. Psychol. Sci. 24, 13011308. doi: $10.1177 / 0956797612466268$

Robinson, J. P., and Godbey, G. (1999). Time for Life. University Park, PA: Pennsylvania State University Press.

Rose, H., and Betts, J. R. (2004). The effect of high school courses on earnings. Rev. Econ. Statist. 86, 497-513. doi: 10.1162/00346530432303 1076

Rowe, M. L., Leech, K. A., and Cabrera, N. J. (2017). Going beyond input quantity: wh-questions matter for toddlers' language and cognitive development. Cogn. Sci. 41, 162-179. doi: 10.1111/cogs.12349

Sarama, J., and Clements, D. H. (2009). Early Childhood Mathematics Education Research: Learning Trajectories for Young Children. New York, NY: Routledge.

Strouse, G. A., O’Doherty, K., and Troseth, G. L. (2013). Effective coviewing: preschoolers' learning from video after a dialogic questioning intervention. Dev. Psychol. 49, 2368-2382. doi: 10.1037/a0032463

Susperreguy, M. I., Douglas, H., Xu, C., Natalia, M-R., and Lefevre, J. (2020). Expanding the home numeracy model to chilean children: relations among parental expectations, attitudes, activities, and children's mathematical outcomes. Early Child Res. Q. 50, 16-28. doi: 10.1016/j.ecresq.2018. 06.010

Susperreguy, M. I., and Davis-Kean, P. E. (2016). Maternal math talk in the home and math skills in preschool children. Early Educ. Dev. 27, 841-857. doi: 10.1080/10409289.2016.1148480

Thippana, J., Elliott, L., Gehman, S., Libertus, K., and Libertus, M. (2020). Parents' use of number talk with young children: comparing methods, family factors, activity contexts, and relations to math skills. Early Childh. Res. Q. 53, 249-259. doi: 10.1016/j.ecresq.2020.05.002

Tompkins, V., Bengochea, A., Nicol, S., and Justice, L. M. (2017). Maternal inferential input and children's language skills. Read. Res. Q. 52, 397-416. doi: 10.1002/rrq. 176

Tudge, J. R. H., and Doucet, F. (2004). Early mathematical experiences: observing young black and white children's everyday activities. Early Childh. Res. Q. 19, 21-39. doi: 10.1016/j.ecresq.2004.01.007
U. S. Bureau of Labor Statistics (2016). American Time Use Survey User Guide: Understanding ATUS 2003 to 2015. Washington, DC: U. S. Bureau of Labor Statistics.

Vandermaas-Peeler, M., Boomgarden, E., Finn, L., and Pittard, C. (2012). Parental support of numeracy during a cooking activity with four-year-olds. Intern. J. Early Years Educ. 20, 78-93.

Vandermaas-Peeler, M., Nelson, J., Bumpass, C., and Sassine, B. (2009). Numeracyrelated exchanges in joint storybook reading and play. Intern. J. Early Years Educ. 17, 67-84. doi: 10.1080/09669760802699910

Verdine, B. N., Zimmermann, L., Foster, L., Marzouk, M. A., Golinkoff, R. M., Hirsh-Pasek, K., et al. (2019). Effects of geometric toy design on parent-child interactions and spatial language. Early Childh. Res. Q. 46, 126-141.

Watts, T. W., Duncan, G. J., Siegler, R. S., and Davis-Kean, P. E. (2016). What's past is prologue. Educ. Res. 43, 352-360.

Weinberger, C. J. (2014). The increasing complementarity between cognitive and social skills. Rev. Econ. Statist. 96, 849-861.

Zippert, E. L., Daubert, E. N., Scalise, N. R., Noreen, G. D., and Ramani, G. B. (2019). "Tap space number three": promoting math talk during parent-child tablet play. Dev. Psychol. 55, 1605-1614. doi: 10.1037/dev0000769

Zippert, E. L., Douglas, A. A., Smith, M. R., and Rittle-Johnson, B. (2020). Preschoolers' broad mathematics experiences with parents during play. J. Exp. Child Psychol. 192:104757.

Zippert, E. L., and Ramani, G. B. (2017). Parents' estimations of preschoolers' number skills relate to at-home number-related activity engagement. Infant Child Dev. 26:24. doi: 10.1002/icd.1968

Zippert, E. L., and Rittle-Johnson, B. (2020). The home math environment: more than numeracy. Early Childh. Res. Q. 50, 4-15.

Zosh, J. M., Verdine, B. N., Filipowicz, A., Golinkoff, R. M., Hirsh-Pasek, K., and Newcombe, N. S. (2015). Talking shape: parental language with electronic versus traditional shape sorters. Mind Brain Educ. 9, 136-144.

Conflict of Interest: The authors declare that the research was conducted in the absence of any commercial or financial relationships that could be construed as a potential conflict of interest.

Copyright (c) 2020 Bachman, Elliott, Duong, Betancur, Navarro, Votruba-Drzal and Libertus. This is an open-access article distributed under the terms of the Creative Commons Attribution License (CC BY). The use, distribution or reproduction in other forums is permitted, provided the original author(s) and the copyright owner(s) are credited and that the original publication in this journal is cited, in accordance with accepted academic practice. No use, distribution or reproduction is permitted which does not comply with these terms. 